\title{
Survival Response of Patients With Gastric Cancer Treated With Regional Arterial-Perfusion Chemotherapy Is Correlated With Borrmann Classification
}

\author{
YE MA ${ }^{1}$, XIANXIAN LIANG ${ }^{1}$, LI LIU ${ }^{2}$, DAZHI GAO ${ }^{2}$, TAO YANG ${ }^{1,2}$, ROBERT M. HOFFMAN $^{3,4}$ and JIAN XU ${ }^{1,2}$ \\ ${ }^{1}$ College of Medical Imaging, Xuzhou Medical University, Xuzhou, P.R. China; \\ ${ }^{2}$ Department of Interventional Therapy, Department of Radiology, Jinling Hospital, Nanjing, P.R. China \\ ${ }^{3}$ AntiCancer Inc., San Diego, CA, U.S.A.; \\ ${ }^{4}$ Department of Surgery, UCSD, San Diego, CA, U.S.A.
}

\begin{abstract}
Background/Aim: The aim of the present study was to correlate the survival response to regional arterial-perfusion chemotherapy (RAPC) with Borrmann classification in patients with gastric cancer. Patients and Methods: The survival response of 270 patients with advanced gastric cancer treated with RAPC was analyzed and Borrmann classification of the tumors was retrospectively correlated to survival. Results: The median survival time of RAPC-treated patients with Borrmann type I/II was 53 months compared with 19 and 12 months for those with Borrmann type III and IV, respectively $(p<0.001)$. Conclusion: Borrmann classification is a potential indicator to predict prognosis of patients with advanced gastric cancer treated with $R A P C$.
\end{abstract}

Gastric cancer is the fifth most-common malignant tumor and the third-highest cause of cancer death in the world (1). Radical resection is the most effective treatment for gastric cancer (24). For patients with unresectable gastric cancer, chemotherapy is first-line treatment. Regional arterial-perfusion chemotherapy (RAPC) is emerging as a promising strategy for gastric cancer.

The Borrmann classification is used for classification of advanced gastric cancer. Borrmann type I tumors mainly protrude into the gastric cavity, and grow in polypoid, umbrella or node shape. Borrmann type II tumors contain ulcers on their surface and the margin of the tumor is clear without infiltration

This article is freely accessible online.

Correspondence to: Jian $\mathrm{Xu}$, College of Medical Imaging, Xuzhou Medical University, Xuzhou 221004, P.R. China; Department of Interventional Therapy, Department of Radiology, Jinling Hospital, Nanjing 210002, P.R. China. E-mail: 13851656307@163.com

Key Words: Gastric cancer, Borrmann classification, arterial perfusion, response, overall survival. into the surrounding tissue. Borrmann type III tumors have an unclear margin and ulcers on their surface which infiltrate deeply into surrounding tissue. Borrmann type IV tumors do not have deep ulcers on their surface and are characterized by disordered mucosal folds, a narrowed gastric cavity, and loss of elasticity. The Borrmann classification has been developed as a prognostic factor for gastric cancer $(1,5,6)$.

The efficacy of RAPC in patients undergoing gastric cancer has not been correlated to different Borrmann types. The present retrospective study aimed to correlate the survival outcome of patients treated with RAPC with Borrmann classification.

\section{Patients and Methods}

Patients. From January 2013 to September 2020, 316 patients who received RAPC at the Department of Interventional Therapy of Jinling Hospital were enrolled in the present study. Patients with the following criteria were included: i) Patients who were diagnosed with gastric cancer by gastroscopy biopsy; ii) patients with gastric cancer with a complete medical record; iii) patients with gastric cancer with no history of surgery or chemo-radiotherapy. Exclusion criteria were: i) Age under 18 or over 80 years; ii) distant metastasis (M1) of gastric cancer. In total, 270 patients with gastric cancer were studied. The study was approved by the Research Ethics Committee of Jinling Hospital (approval number: 2014ZFYJ-012).

Chemotherapy schedule. Each RAPC cycle lasted for 3 weeks. Most patients received at least three cycles of RAPC and were subjected to further evaluation. A small number of patients did not take three cycles of chemotherapy due to obvious improvement of clinical symptoms or intolerance to chemotherapy. Drugs used for RAPC included oxaliplatinum $\left(100 \mathrm{mg} / \mathrm{m}^{2}\right)$, epirubicin $\left(30 \mathrm{mg} / \mathrm{m}^{2}\right)$ and etoposide $(80$ $\mathrm{mg} / \mathrm{m}^{2}$ ). RAPC was administered as follows: After sterilization and local anesthesia with $2 \%$ lidocaine, a $5 \mathrm{~F}$ vascular sheath was inserted into the right femoral artery using a modified Seldinger technique. The interventional catheter was directed to the celiac trunk. Contrast medium was administered in order to perform high-pressure angiography. Angiographic imaging of the left gastric artery or right 
A

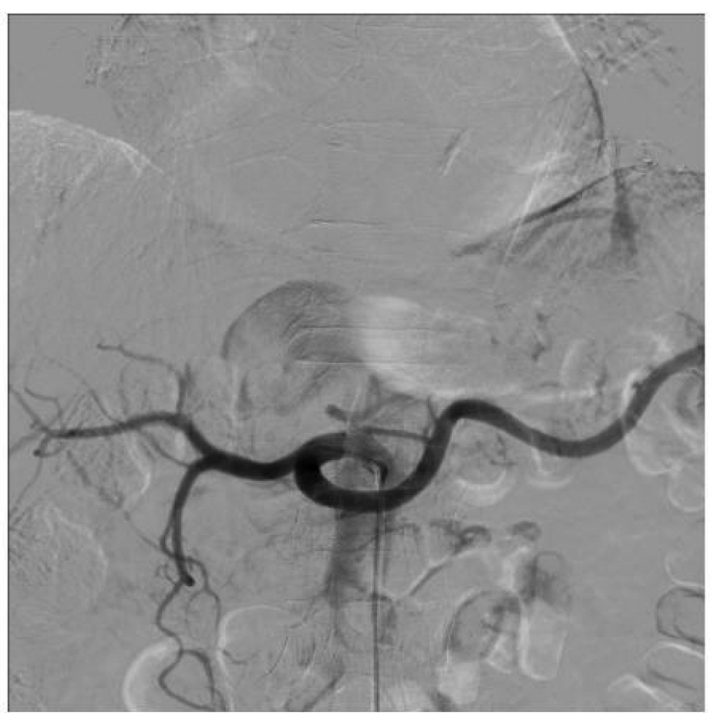

B

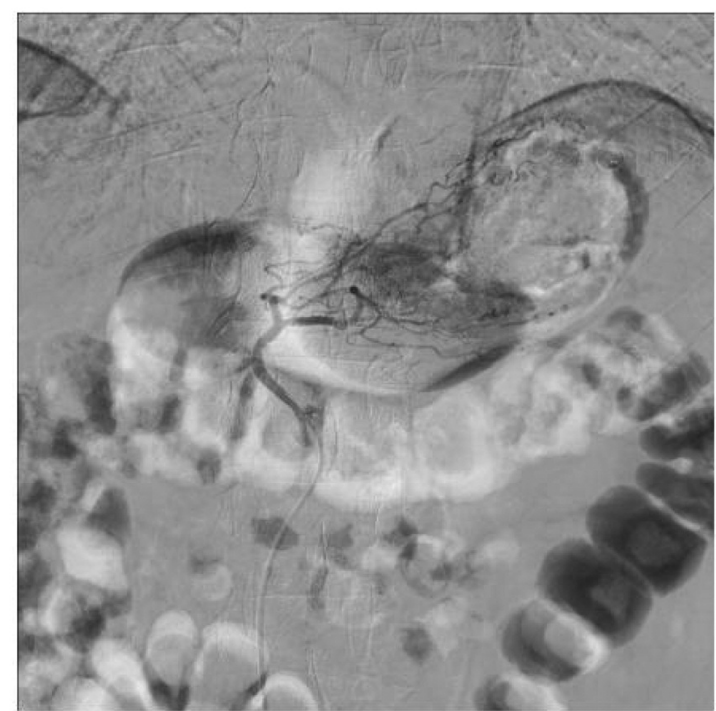

Figure 1. Angiographic images obtained during regional arterial-perfusion chemotherapy. A: The catheter was placed at the opening of the celiac artery. B: The catheter was inserted into the left gastric artery and perfused with contrast medium.

gastroepiploic artery determined artery patency (Figure 1). Subsequently, chemotherapy was injected through the catheter within 10-20 min.

Surgery. The patients were systematically evaluated within 7-10 days after the last cycle of RAPC as candidates for surgery. Gastrectomy or lymph-node dissection was performed only when an $\mathrm{R} 0$ resection was possible.

Follow-up. Postoperative follow-up was on an outpatient basis by e-mail or telephone interview. The latest follow-up information was updated on March 1, 2021. Follow-up was implemented at an interval of 3-6 months in the first 2 years, 6-12 months in the next 3-5 years, and was subsequently once per year.

Statistical analysis. The Fisher exact test was utilized to analyze clinical parameters. The Kaplan-Meier method was used to calculate the cumulative overall survival (OS) rate, and the log-rank test was used to compare the survival curves. OS was evaluated from the beginning of RAPC to the time of death or to the last follow-up. The logistic rank test $(p \leq 0.05)$ was used for multivariate Cox proportional hazards regression analysis to evaluate the independence of prognostic factors. In multivariate analysis, a 95\% confidence interval was used to calculate the hazard ratio. SPSS (version 25.0; IBM, Armonk, NY, USA) and RStudio (version 3.6.3; Rstudio, Boston, MA, USA) were used for all statistical analysis, A value of $p \leq 0.05$ was considered significant.

\section{Results}

Clinico-pathological features. The basic characteristics of the patients are shown in Table I. Due to the small number of patients with Borrmann type I tumors were combined with those with Borrmann type II. Thus patients were divided into three groups: Borrmann type I/II, Borrmann type III and Borrmann type IV.

Among 270 patients with advanced gastric cancer, 42 (15.5\%) were Borrmann type I/II; 207 (76.7\%) were Borrmann type III; and 21 (7.8\%) were Borrmann type IV. Compared with patients with Borrmann type I/II disease, significant differences in tumor size, T-stage, N-stage, TNM stage, histological type and lymph-node metastasis were found in those with Borrmann type III and IV disease. Patients with Borrmann type III and IV gastric cancer had larger tumors, advanced TNM stage, and a higher level of lymph-node metastasis, than patients with Borrmann type I/II disease.

The treatment plan and prognosis of the patients is shown in Table II. Among the 42 patients with Borrmann type I/II, all underwent conversion surgery, including 20 total gastrectomies and 22 partial gastrectomies. The overall frequency of R0 resection was $100 \%$ for Borrmann type I/II. Among the patients with Borrmann type III, 149 underwent radical gastrectomy, including total gastrectomy in 88 cases and partial gastrectomy in 61 cases. R0 resection was achieved in 145 patients and R1/2 resection in four patients. For patients with Borrmann type IV disease, 11 underwent radical resection, resulting in nine $\mathrm{R} 0$ and two $\mathrm{R} 1 / 2$ resections.

Compared with patients with type I/II disease, there was a significant difference in the surgical conversion rate between Borrmann type III and IV patients $(p<0.001)$. The rate of $\mathrm{R} 0$ resection in patients with Borrmann type IV gastric cancer was significantly lower than in other Borrmann types $(p=0.004)$. 
Table I. Comparison of clinico-pathological factors among different Borrmann types of gastric cancer.

\begin{tabular}{|c|c|c|c|c|}
\hline \multirow[b]{2}{*}{ Variable } & \multirow[b]{2}{*}{ Subgroup } & \multicolumn{3}{|c|}{ Borrmann type } \\
\hline & & $\mathrm{I}+\mathrm{II}(\mathrm{n}=42), \mathrm{n}(\%)$ & III (n=207), n (\%) & IV $(n=21), n(\%)$ \\
\hline \multirow[t]{2}{*}{ Gender } & Male & $30(71.4)$ & $158(76.3)$ & $13(61.9)$ \\
\hline & Female & $12(28.6)$ & $49(23.7)$ & $8(38.1)$ \\
\hline \multirow[t]{2}{*}{ Age } & $\leq 60$ Years & $22(52.4)$ & $99(47.8)$ & $12(57.1)$ \\
\hline & $>60$ Years & $20(47.6)$ & $108(52.2)$ & $9(42.9)$ \\
\hline & Upper & $15(35.7)$ & $92(44.4)$ & $7(33.3)$ \\
\hline \multirow{3}{*}{ in the stomach } & Middle & $18(42.8)$ & $76(36.7)$ & $11(52.4)$ \\
\hline & Lower & $7(16.7)$ & $33(15.9)$ & $0(0)$ \\
\hline & Entire & $2(4.8)$ & $6(2.9)$ & $3(14.3)$ \\
\hline \multirow[t]{2}{*}{ Tumor size } & $\leq 5 \mathrm{~cm}$ & $41(97.6)$ & $142(68.6)$ & $4(19.0)$ \\
\hline & $>5 \mathrm{~cm}$ & $1(2.4)$ & $65(31.4)$ & $17(81.0)$ \\
\hline \multirow[t]{3}{*}{ T-Stage } & 2 & $6(14.3)$ & $8(3.9)$ & $1(4.8)$ \\
\hline & 3 & $34(81.0)$ & $180(87.0)$ & $14(66.7)$ \\
\hline & 4 & $2(4.8)$ & $19(9.2)$ & $6(28.6)$ \\
\hline \multirow[t]{5}{*}{$\mathrm{N}$-Stage } & 0 & $25(59.5)$ & $69(33.3)$ & $5(23.8)$ \\
\hline & 1 & $7(16.7)$ & $33(15.9)$ & $1(4.8)$ \\
\hline & 2 & $3(7.1)$ & $48(23.2)$ & $3(14.3)$ \\
\hline & 3 & $6(14.3)$ & $52(25.1)$ & $8(38.1)$ \\
\hline & 4 & $1(2.4)$ & $5(2.4)$ & $4(19.0)$ \\
\hline \multirow[t]{5}{*}{ TNM stage } & IIA & $29(69.0)$ & $74(35.7)$ & $5(23.8)$ \\
\hline & IIB & $4(9.5)$ & $28(13.5)$ & $1(4.8)$ \\
\hline & IIIA & $3(7.1)$ & $49(23.7)$ & $3(14.3)$ \\
\hline & IIIB & $5(11.9)$ & $51(24.6)$ & $8(38.1)$ \\
\hline & IIIC & $1(2.4)$ & $5(2.4)$ & $4(19.0)$ \\
\hline \multirow[t]{7}{*}{ Pathological type } & Well-differentiated AC & $1(2.4)$ & $5(2.4)$ & $0(0)$ \\
\hline & Moderately-well-differentiated AC & $1(2.4)$ & $3(1.4)$ & $0(0)$ \\
\hline & Moderately differentiated AC & $9(21.4)$ & $31(15.0)$ & $1(4.8)$ \\
\hline & Moderately-poorly differentiated AC & $14(33.3)$ & $39(18.8)$ & $0(0)$ \\
\hline & Poorly differentiated AC & $15(35.7)$ & $114(55.1)$ & $9(42.9)$ \\
\hline & Mucinous AC & $0(0)$ & $6(2.9)$ & $1(4.8)$ \\
\hline & Signet-ring cell carcinoma & $2(4.8)$ & $9(4.3)$ & $10(47.6)$ \\
\hline \multirow[t]{2}{*}{ Lympho-vascular invasion } & Positive & $17(40.5)$ & $138(66.7)$ & $16(76.2)$ \\
\hline & Negative & $25(59.5)$ & $69(33.3)$ & $5(23.8)$ \\
\hline
\end{tabular}

AC: Adenocarcinoma.

The median survival of patients with Borrmann type I/II treated with RAPC was significantly longer at 53 months, compared with 19 and 12 months for those with Borrmann type III and IV, respectively ( $p<0.001)$ (Figure 2).

Uni-variate analyses (Table III) revealed that tumor size $(p<0.001)$, T-stage $(p<0.001), \mathrm{N}$ stages $(p<0.001), \mathrm{TNM}$ stages $(p<0.001)$, pathological type $(p<0.001)$, lymphovascular invasion $(p<0.001)$, frequency of interventional therapy $(p=0.00682)$, surgery $(p<0.001)$, and Borrmann type $(p<0.001)$ were significantly related to survival of patients treated with RAPC. Tumor size $(p=0.002)$, T-stage $(p<0.001)$, lympho-vascular invasion $(p=0.006)$, type of operation $(p=0.002)$ and Borrmann type $(p=0.009)$ were independent prognostic factors for patients with advanced gastric cancer who had received RAPC. TNM stage $(p=0.170)$ was not independently predictive of OS, even though OS was reported to be an independent predictor in another gastric-cancer study (5).

For patients who underwent radical resection after successful transformation by RAPC, residual margin and Borrmann type were both independent predicators, further indicating the use of Borrmann type to predict the outcome of patients who underwent radical resection. Multi-variate analyses showed that surgery $(p=0.002)$ was an independent prognostic factor, while the surgical method $(p=0.787)$ was not, indicating the importance of radical resection regardless of the surgical method.

Long-term outcome. To explore the relationship between Borrmann classification and OS, the patients were divided into groups according to tumor size, lymph-node metastasis, and whether they underwent conversion surgery or not. All 
Table II. Comparison of treatment among different Borrmann types of gastric cancer.

\begin{tabular}{|c|c|c|c|c|}
\hline Variable & Treatment & $\begin{array}{c}\text { Borrmann I+II } \\
(\mathrm{n}=42), \mathrm{n}(\%)\end{array}$ & $\begin{array}{l}\text { Borrmann III } \\
(\mathrm{n}=207), \mathrm{n}(\%)\end{array}$ & $\begin{array}{l}\text { Borrmann IV } \\
(\mathrm{n}=21), \mathrm{n}(\%)\end{array}$ \\
\hline \multirow{6}{*}{$\begin{array}{l}\text { Non-arterial chemotherapy, } \\
\mathrm{n}(\%)\end{array}$} & CapeOX ${ }^{\mathrm{a}}$ & $3(7.1)$ & $9(4.3)$ & $1(4.8)$ \\
\hline & FLEEOX $^{\mathrm{b}}$ & $8(19.0)$ & $7(8.2)$ & $2(9.5)$ \\
\hline & FOLFOX $4^{\mathrm{c}}$ & $14(33.3)$ & $11(5.3)$ & $5(23.8)$ \\
\hline & S-1 & $15(35.7)$ & $148(71.5)$ & $13(61.9)$ \\
\hline & Capecitabine & $1(2.4)$ & $16(7.7)$ & $0(0)$ \\
\hline & Raltitrexed & $1(2.4)$ & $16(7.7)$ & $0(0)$ \\
\hline \multirow{2}{*}{ Arterial chemotherapy, n (\%) } & Oxaliplatinum & $42(100)$ & $185(89.4)$ & $21(100)$ \\
\hline & Lobaplatinum & $0(0)$ & $22(10.6)$ & $0(0)$ \\
\hline \multirow{3}{*}{$\begin{array}{l}\text { Interventional therapy frequency, } \\
\mathrm{n}(\%)\end{array}$} & $<3$ & $4(9.5)$ & $22(10.6)$ & $0(0)$ \\
\hline & 3 & $27(64.3)$ & $136(65.7)$ & $10(47.6)$ \\
\hline & $>3$ & $11(26.2)$ & $49(23.7)$ & $11(52.4)$ \\
\hline \multirow[t]{2}{*}{ Surgical operation, n (\%) } & Yes & $42(100)$ & $149(72.0)$ & $11(52.4)$ \\
\hline & No & $0(0)$ & $58(28.0)$ & $10(47.6)$ \\
\hline \multirow[t]{2}{*}{ Surgical method, n (\%) } & Total gastrectomy & $20(47.6)$ & $88(42.5)$ & $8(38.1)$ \\
\hline & Partial resection & $22(52.4)$ & $61(29.5)$ & $3(14.3)$ \\
\hline \multirow[t]{2}{*}{ Residual margin, $\mathrm{n}(\%)$} & R0 & $42(100)$ & $145(70.0)$ & $9(42.9)$ \\
\hline & $\mathrm{R} 1 / 2$ & $0(0)$ & $4(1.9)$ & $2(9.5)$ \\
\hline
\end{tabular}

a $130 \mathrm{mg} / \mathrm{m}^{2}$ oxaliplatinum, i.v., day $1 ; 850-1,000 \mathrm{mg} / \mathrm{m}^{2}$ capecitabine, p.o. b.i.d., days $1-14$. Repeat cycle every 3 weeks. ${ }^{b} 370 \mathrm{mg} / \mathrm{m}^{2}$ fluorouracil, i.v., days $1-5 ; 200 \mathrm{mg} / \mathrm{m}^{2}$ calcium folinate, i.v., days $1-5 ; 120 \mathrm{mg} / \mathrm{m}^{2}$ oxaliplatinum $+30 \mathrm{mg} / \mathrm{m}^{2}$ epirubicin $+70 \mathrm{mg} / \mathrm{m}^{2}$ etoposide, $i . v$. through arteria gastric sinistra, days 6 and 20. Repeat cycle every 5 weeks for two courses. ${ }^{c} 85 \mathrm{mg} / \mathrm{m}^{2}$ oxaliplatinum, i.v., day $1 ; 200 \mathrm{mg} / \mathrm{m}^{2}$ calcium folinate, i.v., day $1 ; 400$ $\mathrm{mg} / \mathrm{m}^{2}$ fluorouracil, i.v. bolus, days 1 and $2 ; 600 \mathrm{mg} / \mathrm{m}^{2}$ fluorouracil, i.v. for 22 consecutive hours, days 1 and 2 .

Table III. Uni-variate and multi-variate Cox proportional hazard analyses of clinical features for all gastric-cancer patients.

\begin{tabular}{|c|c|c|c|c|c|}
\hline \multirow[t]{2}{*}{ Prognostic factor } & \multirow[b]{2}{*}{ Comparison } & \multicolumn{2}{|c|}{ Uni-variate } & \multicolumn{2}{|c|}{ Multi-variate } \\
\hline & & HR $(95 \% \mathrm{CI})$ & $p$-Value & HR $(95 \% \mathrm{CI})$ & $p$-Value \\
\hline Gender & Male $v s$. female & $0.852(0.588-1.23)$ & 0.397 & & \\
\hline Age & $>60$ vs. $\leq 60$ Years & $0.729(0.526-1.01)$ & 0.059 & & \\
\hline Tumor location & Upper, middle, lower $v s$. entire & $0.819(0.666-1.01)$ & 0.058 & & \\
\hline Tumor size & $>5 v s . \leq 5 \mathrm{~cm}$ & $7.763(5.249-11.480)$ & $<0.001$ & $2.117(1.316-3.407)$ & 0.002 \\
\hline T-Stage & 3,4 vs. 2 & $8.491(4.633-15.559)$ & $<0.001$ & $9.004(4.731-17.137)$ & $<0.001$ \\
\hline N-Stage & $1,2,3,4$ vs. 0 & $2.119(1.846-2.433)$ & $<0.001$ & $3.009(0.921-9.833)$ & 0.068 \\
\hline TNM stage & IIB, IIIA, IIIB, IIIC $v s$. IIA & $2.126(1.860-2.430)$ & $<0.001$ & $0.460(0.151-1.395)$ & 0.170 \\
\hline Pathological type & All other types vs. well-differentiated AC & $1.337(1.169-1.528)$ & $<0.001$ & $1.071(0.907-1.265)$ & 0.420 \\
\hline Lympho-vascular invasion & Positive $v s$. negative & $6.386(4.063-10.036)$ & $<0.001$ & $3.054(1.381-6.752)$ & 0.006 \\
\hline Non-arterial chemotherapy & $\begin{array}{l}\text { FLEEOX }^{\mathrm{a}}, \text { FOLFOX } 4^{\mathrm{b}}, \mathrm{S}-1, \text { capecitabine, } \\
\text { raltitrexed } v s . \text { CapeOX }{ }^{\mathrm{c}}\end{array}$ & $0.958(0.821-1.12)$ & 0.59 & & \\
\hline Interventional therapy frequency & $<3 />3$ vs. 3 & $1.319(1.079-1.613)$ & 0.00682 & $1.073(0.865-1.332)$ & 0.520 \\
\hline Operation & Yes $v s$. no & $0.161(0.111-0.234)$ & $<0.001$ & $22.548(3.284-154.836)$ & 0.002 \\
\hline Borrmann type & $\mathrm{III}+\mathrm{IV} v s . \mathrm{I}+\mathrm{II}$ & $2.805(2.013-3.909)$ & $<0.001$ & $1.762(1.152-2.695)$ & 0.009 \\
\hline
\end{tabular}

AC: Adenocarcinoma; CI: confidence intervaI; HR: hazard ratio. ${ }^{3} 370 \mathrm{mg} / \mathrm{m}^{2}$ fluorouracil, i.v., days $1-5 ; 200 \mathrm{mg} / \mathrm{m}^{2}$ calcium folinate, i.v., days 1 $5 ; 120 \mathrm{mg} / \mathrm{m}^{2}$ oxaliplatinum $+30 \mathrm{mg} / \mathrm{m}^{2}$ epirubicin $+70 \mathrm{mg} / \mathrm{m}^{2}$ etoposide, i.v. through arteria gastric sinistra, days 6 and 20 . Repeat cycle every 5 weeks for two courses. ${ }^{b} 85 \mathrm{mg} / \mathrm{m}^{2}$ oxaliplatinum, $i . v$., day $1 ; 200 \mathrm{mg} / \mathrm{m}^{2}$ calcium folinate, i.v., day $1 ; 400 \mathrm{mg} / \mathrm{m}^{2}$ fluorouracil, $i . v$. bolus, days 1 and $2 ; 600 \mathrm{mg} / \mathrm{m}^{2}$ fluorouracil, i.v. for 22 consecutive hours, days 1 and $2 .{ }^{\mathrm{c}} 130 \mathrm{mg} / \mathrm{m}^{2}$ oxaliplatinum, i.v., day $1 ; 850-1,000 \mathrm{mg} / \mathrm{m}^{2}$ capecitabine, p.o. b.i.d., days 1-14. Repeat cycle every 3 weeks.

42 patients with Borrmann type I/II disease underwent conversion surgery, resulting in a median survival of 53 months. Among the 207 patients with Borrmann type III, the median survival of 149 patients who underwent conversion surgery was 22 months, and for 58 patients who did not, it was 15 months. Among the 21 patients with Borrmann type IV, the median survival of patients who underwent conversion surgery $(n=11)$ or did not $(n=10)$ was 22 and 8 


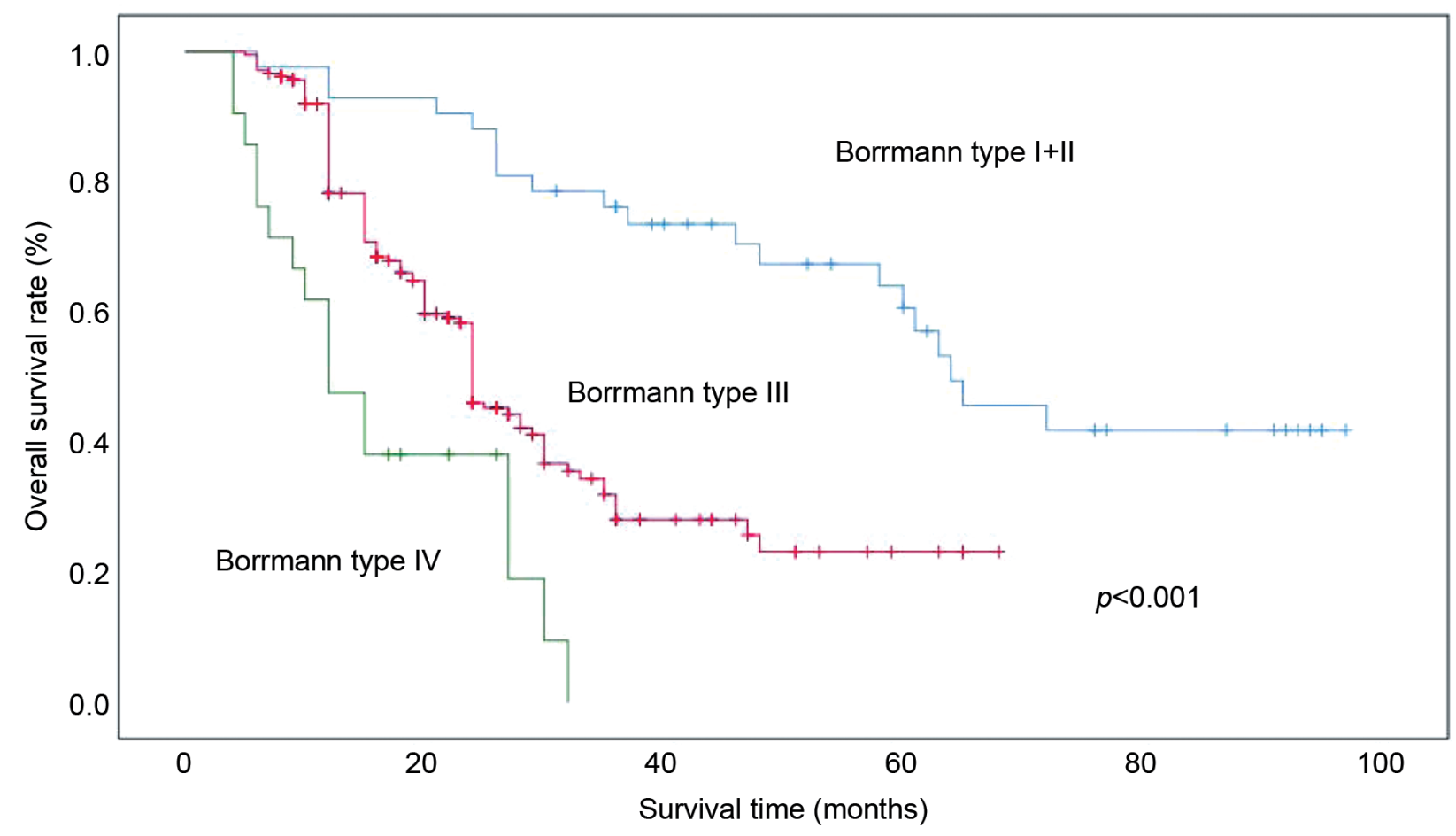

Figure 2. Comparison of survival curves among patients with different Borrmann types of gastric cancer.

months, respectively. The OS of patients with Borrmann type I/II was significantly longer than that of patients with type III and type IV $(p<0.01)$ (Figure 3$)$.

There was a significant difference in the OS according to Borrmann type among the 171 patients with lymph-node metastasis: 17 with Borrmann type I/II had a median survival of 31 months; 138 with Borrmann type III had a median survival of 15.5 months; and 16 with Borrmann type IV had a median survival of 12 months $(p<0.01)$. Among 99 patients without lymph-node metastasis, the median survival of those with Borrmann type I/II (63.5 months) was also significantly longer than that of those with Borrmann type III (25 months) and type IV (27 months) $(p<0.01)$ (Figure 3).

Of the 187 patients with tumor size $\leq 5 \mathrm{~cm}, 41$ who were classified into the Borrmann type I/II group had a median survival of 54 months. The median survival of the 142 patients with type III was 23.5 months and of the four with Borrmann type IV was 22.5 months $(p<0.001)$. However, in 83 patients with tumor size $>5 \mathrm{~cm}$, the median survival of the sole patient with Borrmann type I/II was 12.5 months. The median survival of the 65 patients with Borrmann type III and the 17 patients with Borrmann type IV was 12 months for both $(p=0.884)$ (Figure 3).

\section{Discussion}

The present study determined that the overall surgicalconversion success rate of RAPC was $74.8 \%$, and that RAPC appears to be effective for gastric cancer.

Borrmann classification is standard for predicting prognosis in gastric cancer. Song et al. reported that Borrmann classification could be used as a simple predictor of survival in patients with advanced gastric cancer (5). Liang et al. reported that Borrmann classification served as an independent risk factor for patients with positive surgical margins (2). The present study indicated that the clinical outcome of RAPC in patients with different Borrmann types was significantly different. Huang et al. found that lymph-node metastasis was an independent risk factor limiting the prognosis of patients with Borrmann IV disease (7). In the present study, the median survival of patients with Borrmann type IV gastric cancer without lymph-node metastasis was 27 months compared to 12 months for their counterparts with lymph-node metastasis. Both Luo et al. (8) and Liang et al. (9) found that radical resection improved survival of patients with Borrmann type IV disease. In the present study, the median survival of those who underwent conversion surgery for Borrmann type IV gastric cancer was 22 months, while survival of the patients without 

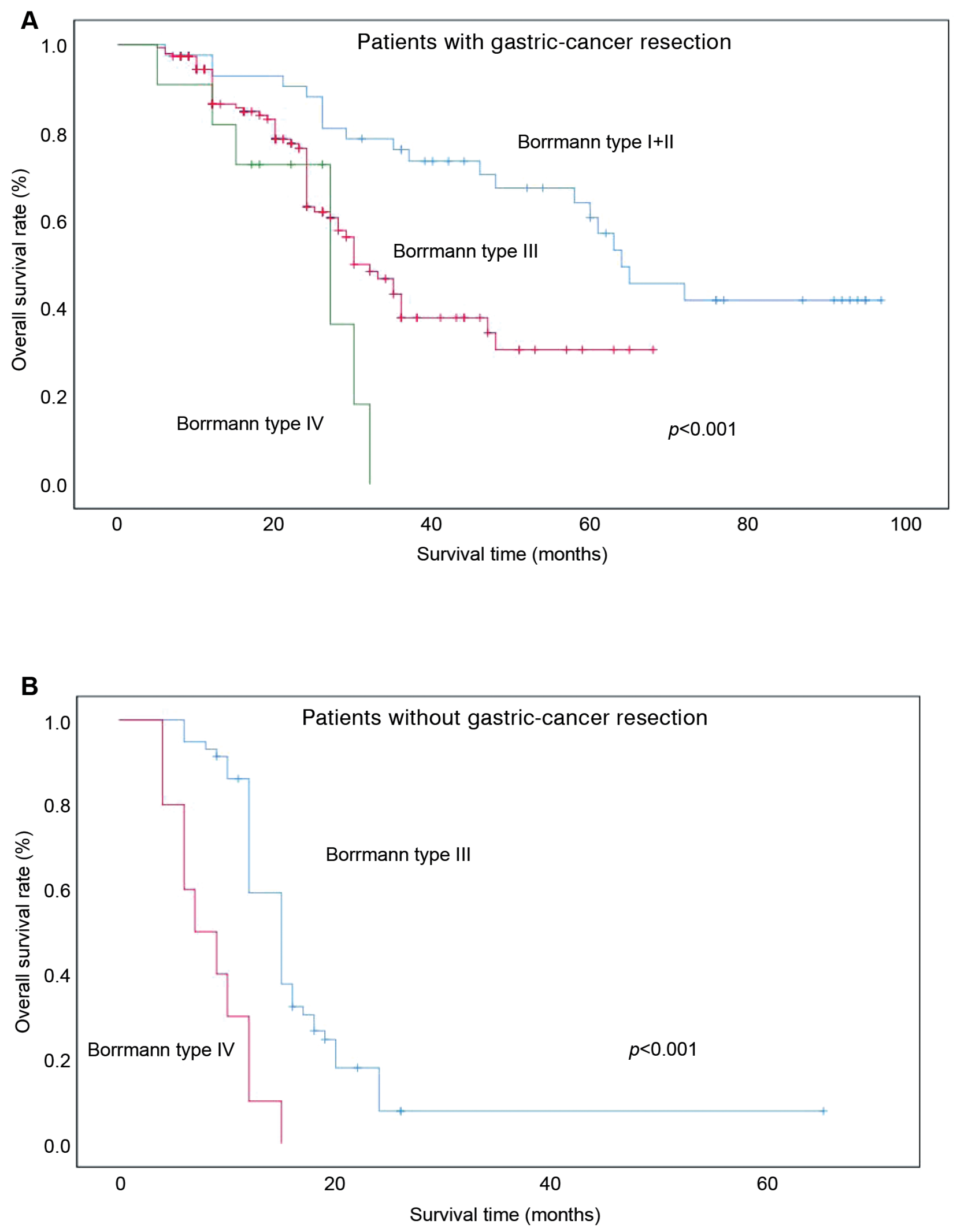

Figure 3. Continued 

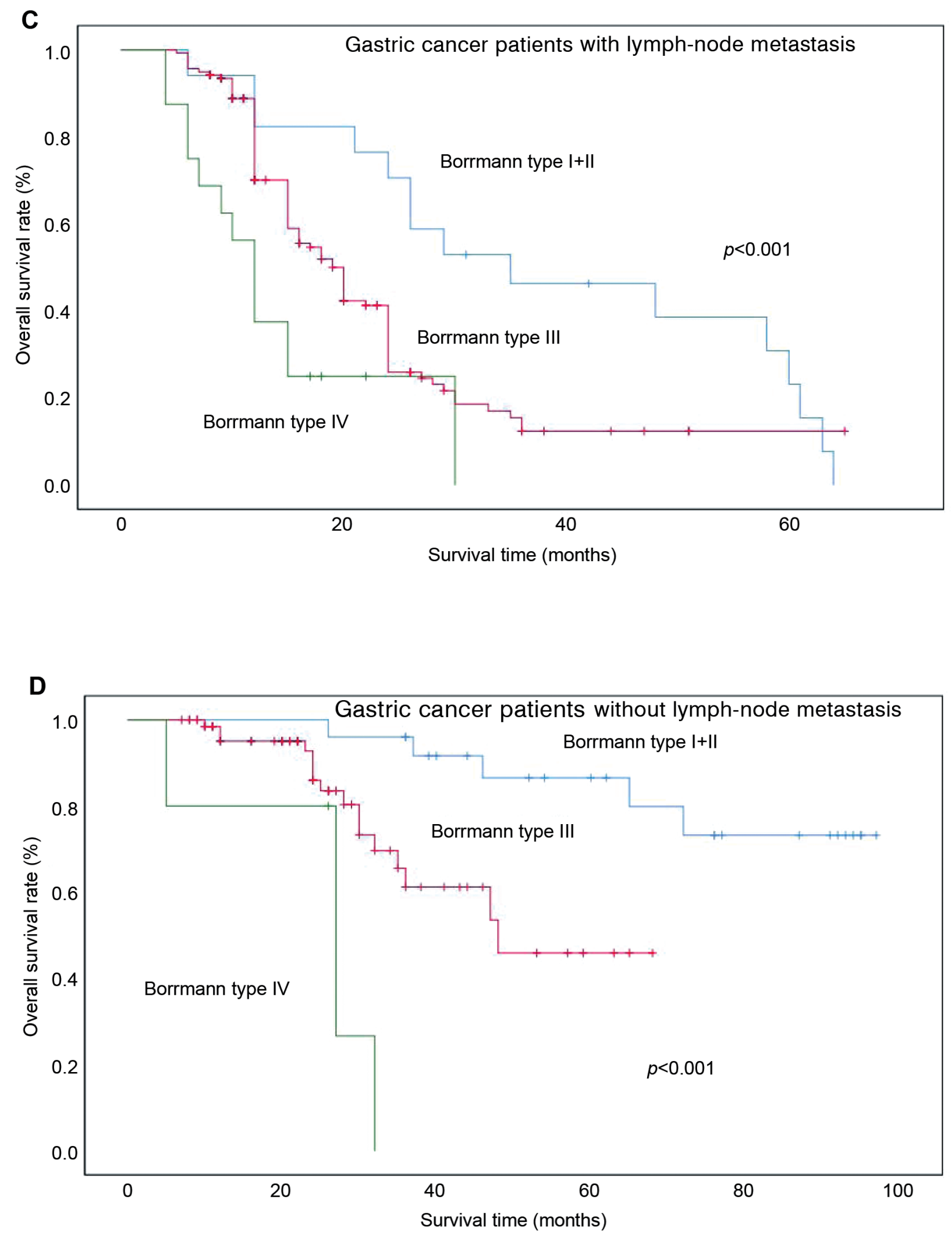

Figure 3. Continued 

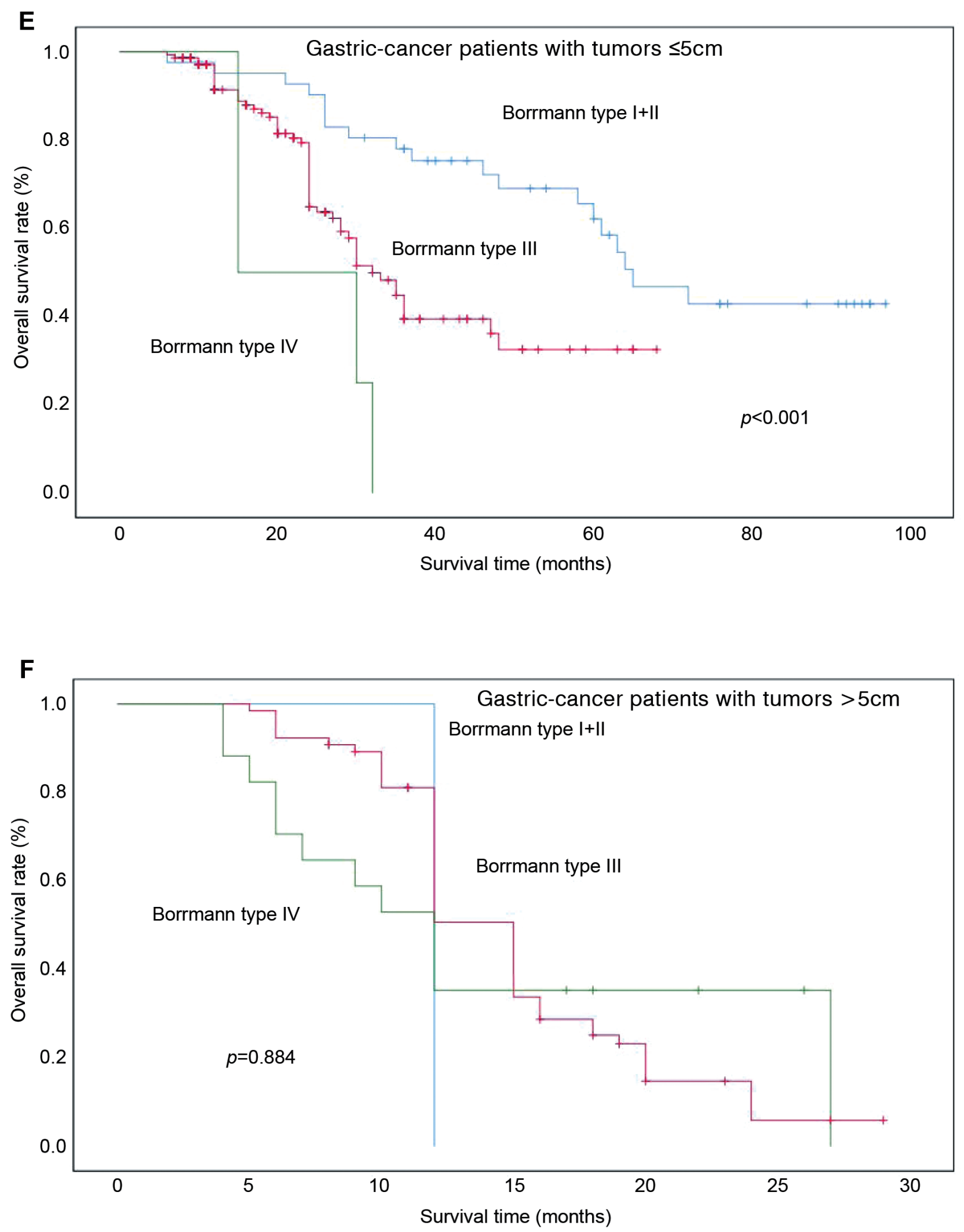

Figure 3. Comparison of survival curves according to Borrmann type in patients who underwent surgery for gastric cancer (A); did not undergo surgery $(B)$; had lymph-node metastasis $(C)$; did not have lymph-node metastasis $(D)$; had tumor $\leq 5 \mathrm{~cm}(E)$; and had tumor $>5 \mathrm{~cm}(F)$. 
conversion surgery was 8 months. Ji et al. observed that there was no difference in the OS of patients with Borrmann types I, II and III (10). In the present study, patients with Borrmann type $\mathrm{I} / \mathrm{II}$ were found to survive more than twice as long as those with Borrmann type III (median survival of 53 vs. 19 months, respectively). Yamashita et al. reported that long-term S-1 chemotherapy improved the prognosis of Borrmann type IV gastric cancer (11). Sun et al. reported that a neoadjuvant chemotherapy combination of docetaxel, cisplatinum and 5fluorouracil/leucovorin was effective for Borrmann type IV disease (12).

In the present retrospective study, we found that when the tumor size was $\leq 5 \mathrm{~cm}$, patients with Borrmann type I/II treated with RAPC had longer OS than those with Borrmann type III and IV. However, no significant difference in OS was found among different Borrmann types in patients with tumor size greater than $5 \mathrm{~cm}$, which was consistent with Chen et al. (13) and Hosoda et al. (14).

The present study suggests that Borrmann classification can be used as a potential indicator to predict prognosis of patients with advanced gastric cancer treated with RAPC.

\section{Conflicts of Interest}

None of the Authors have any conflict of interest with regard to this study.

\section{Authors' Contributions}

YM designed the study; YM, XL, LL, DG and TY collected and analyzed the data; YM drafted the article; RMH revised the article; JX supervised the study.

\section{References}

1 Smyth EC, Nilsson M, Grabsch HI, van Grieken NC and Lordick F: Gastric cancer. Lancet 396(10251): 635-648, 2020. PMID: 32861308. DOI: 10.1016/S0140-6736(20)31288-5

2 Liang Y, Ding X, Wang X, Wang B, Deng J, Zhang L and Liang $\mathrm{H}$ : Prognostic value of surgical margin status in gastric cancer patients. ANZ J Surg 85(9): 678-684, 2015. PMID: 24438078. DOI: $10.1111 /$ ans. 12515

3 Raziee HR, Cardoso R, Seevaratnam R, Mahar A, Helyer L, Law $\mathrm{C}$ and Coburn N: Systematic review of the predictors of positive margins in gastric cancer surgery and the effect on survival. Gastric Cancer 15 Suppl 1: S116-S124, 2012. PMID: 22138928. DOI: $10.1007 / \mathrm{s} 10120-011-0112-7$

4 Morgagni P, Solaini L, Framarini M, Vittimberga G, Gardini A, Tringali D, Valgiusti M, Monti M and Ercolani G: Conversion surgery for gastric cancer: A cohort study from a western center. Int J Surg 53: 360-365, 2018. PMID: 29654967. DOI: 10.1016/ j.ijsu.2018.04.016
5 Song XH, Zhang WH, Kai-Liu, Chen XL, Zhao LY, Chen XZ, Kun-Yang, Zhou ZG and Hu JK: Prognostic impact of Borrmann classification on advanced gastric cancer: a retrospective cohort from a single institution in western China. World J Surg Oncol 18(1): 204, 2020. PMID: 32792016. DOI: 10.1186/s12957-02001987-5

6 Chen CQ, Wu XJ, Yu Z, Bu ZD, Zuo KQ, Li ZY and Ji JF: Prognosis of patients with gastric cancer and solitary lymph node metastasis. World J Gastroenterol 19(46): 8611-8618, 2013. PMID: 24379578. DOI: 10.3748/wjg.v19.i46.8611

7 Huang HB, Gao ZM, Sun AQ, Liang WT and Li K: Subtotal gastrectomy combined with chemotherapy: An effective therapy for patients with circumscribed Borrmann type IV gastric cancer. World J Gastrointest Oncol 12(11): 1325-1335, 2020. PMID: 33250964. DOI: 10.4251/wjgo.v12.i11.1325

8 Luo Y, Gao P, Song Y, Sun J, Huang X, Zhao J, Ma B, Li Y and Wang Z: Clinicopathologic characteristics and prognosis of Borrmann type IV gastric cancer: a meta-analysis. World J Surg Oncol 14(1): 49, 2016. PMID: 26912240. DOI: 10.1186/s12957016-0805-9

9 Liang C, Chen G, Zhao B, Qiu H, Li W, Sun X, Zhou Z and Chen Y: Borrmann type IV gastric cancer: Focus on the role of gastrectomy. J Gastrointest Surg 24(5): 1026-1032, 2020. PMID: 31090037. DOI: 10.1007/s11605-019-04236-7

$10 \mathrm{Kim}$ JH, Lee HH, Seo HS, Jung YJ and Park CH: Borrmann type 1 cancer is associated with a high recurrence rate in locally advanced gastric cancer. Ann Surg Oncol 25(7): 2044-2052, 2018. PMID: 29752601. DOI: 10.1245/s10434-018-6509-3

11 Yamashita K, Hosoda K, Katada N, Moriya H, Mieno H, Higuchi K, Sasaki T, Katada C, Sakuramoto S, Tanabe S, Koizumi W, Kikuchi S and Watanabe M: Survival outcome of Borrmann type IV gastric cancer potentially improved by multimodality treatment. Anticancer Res 35(2): 897-906, 2015. PMID: 25667472.

12 Sun XC, Lin J and Ju AH: Treatment of Borrmann type IV gastric cancer with a neoadjuvant chemotherapy combination of docetaxel, cisplatin and 5-fluorouracil/leucovorin. J Int Med Res 39(6): 2096-2102, 2011. PMID: 22289524. DOI: 10.1177/ 147323001103900605

13 Chen S, Ou-Yang LY, Nie RC, Li YF, Xiang J, Zhou ZW, Chen YB and Peng JS: Tumor size is a critical factor in adjuvant chemotherapy for $\mathrm{T}_{3-4 \mathrm{a}}{ }^{\mathrm{N} 0 \mathrm{M} 0}$ gastric cancer patients after D2 gastrectomy. Gastroenterol Res Pract 2017: 4928736, 2017. PMID: 28331491. DOI: $10.1155 / 2017 / 4928736$

14 Hosoda K, Yamashita K, Katada N, Moriya H, Mieno H, Sakuramoto S, Kikuchi S and Watanabe M: Preoperative tumor size is a critical prognostic factor for patients with Borrmann type III gastric cancer. Surg Today 45(1): 68-77, 2015. PMID: 25352012. DOI: $10.1007 / \mathrm{s} 00595-014-1060-8$

Received June 16, 2021

Revised September 3, 2021 Accepted September 30, 2021 